\title{
Health Behaviors and Chronic Conditions of Movers: Out-of-state Interviews Among Cell Phone Respondents, BRFSS 2014
}

\author{
Pranesh Chowdhury ${ }^{\star}$ Carol Pierannunzi ${ }^{\dagger}$, William S Garvin ${ }^{\ddagger}$, Machell Town ${ }^{* \star}$ \\ Keywords: out of state, cell-phone, brfss \\ DOI: $10.29115 /$ SP-2018-0010
}

\section{Survey Practice}

Vol. 11, Issue 2, 2018

Since 2011, the Behavioral Risk Factor Surveillance System (BRFSS) has been conducting telephone surveys using landline and cell phones from all U.S. states. Due to the portability of cell phones, residents in one state can retain cell phone numbers with area codes from other states. Protocol dictates that BRFSS must interview such out-of-state respondents to complete the core BRFSS interview and collected data must then be transferred to the state of current residence. We used cell phone data from 2014 BRFSS to compare the demographic factors, health care access, health behaviors, history of chronic disease, and chronic conditions among out-of-state interview (movers) with those respondents whose cell phone numbers matched their current state of residence (did not move). The estimated weighted population percentage of movers was $10 \%$ nationwide and ranged from $1.5 \%$ in Hawaii to $21.0 \%$ in Nevada (median: $5.8 \%$ ). Compared with respondents who did not move, movers were significantly more likely to be younger, white non-Hispanic, college graduate, never married, and more likely to have health care coverage. After adjusting for demographics, movers were $16 \%$ less likely to report no leisure time physical activity, $17 \%$ less likely to smoke, $7 \%$ less likely to be overweight or obese, $33 \%$ less likely to report diabetes, and $12 \%$ less likely to report having arthritis than respondents who did not move. Persons who might be left out of cell phone samples due to moving in or out of state may therefore represent a potential for bias in estimation of health behaviors and chronic conditions where transfer of data across state lines is not possible.

\section{INTRODUCTION}

In the United States, telephone surveys had traditionally been conducted with landline telephones only. With declining response rates in landline phone surveys and increasing use of cell phones, telephone surveys have had to add cell phones into their samples to reduce nonresponse and undercoverage bias. However, cell phone respondents are difficult to reach due to safety concerns (such as driving while using); technology barriers (caller ID, call blocking);

\footnotetext{
* Institution: Centers for Disease Control and Prevention

Department: Population Health Surveillance Branch, Division of Population Health, NCCDPHP

† Institution: Centers for Disease Control and Prevention

Department: Population Health Surveillance Branch, Division of Population Health, NCCDPHP

‡ Institution: Centers for Disease Control and Prevention

Department: Population Health Surveillance Branch, Division of Population Health, NCCDPHP

** Institution: Centers for Disease Control and Prevention

Department: Population Health Surveillance Branch, Division of Population Health, NCCDPHP
} 
and number portability (Kempf and Remington 2007). Earlier surveys that included cell phone respondents were more expensive than similar surveys conducted by landline phone only (Guterbock et al. 2011). Currently, cell phone numbers are not tied to respondents' residence or locations, so some of the numbers in the cell phone sample could reach respondents who have moved out of the sampling geography. Therefore, persons who might otherwise be excluded from cell phone samples due to moving may represent a potential for bias in cell phone surveys. Although screening questions can remove respondents from sample jurisdictions where they no longer reside, using them in the sample can make sampling less efficient and will contribute to coverage error (Lavrakas et al. 2007). Incorporation of persons who have moved into a sampling geography is more difficult and can open the door to undercoverage of populations.

Earlier studies have examined the sociodemographic characteristics of this mobile population and its effect on cell-phone sampling and survey estimates. (Christian, Dimock, and Keeter 2009) assessed whether the sample information from cell phone samples matched geographic data derived from respondents' self-reported zip codes. They estimated the geographic inaccuracy rates for cell phone samples (cell only, cell mostly, and landline mostly or dual users) for all adult users to be $6 \%$ at the census region level, $10 \%$ at the state level, and $41 \%$ at the county level. Similarly, (Skalland and Khare 20 13) estimated the national geographic inaccuracy (as sampling state vs. true state) of cell phone samples for adults in cell-only households to be $11.5 \%$ at the national level, with inaccuracy rates varying widely among states. ( $M$ arken, Chattopadhyay, and Chan 2016) reported an increase in cell phone mobility (described as "overcoverage" and "undercoverage") across states from 2013. The out-of-state respondents are were more likely to be male, young, non-Hispanic white, college graduate, have high income, live in a household with no children, and living in Northeast census region (Christian, Dimock, and Keeter 2009; Marken, Chattopadhyay, and Chan 2016; Skalland and Kh are 2013). Inaccuracy in cell telephone sampling or over- and undercoverage possesses a significant challenge in sampling, increases the costs of surveys, and can increase the variance (Skalland and Khare 2013) of state-level survey estimates.

The Behavioral Risk Factor Surveillance System (BRFSS) is an ongoing, state-based, random-digit dialed telephone survey of noninstitutionalized adults aged $\geq 18$ years residing in the United States. BRFSS had traditionally been conducted with landline phones only but has been conducting a dual-frame telephone survey using both landline and cell phones since 2011. Because the BRFSS draws samples independently from each state, protocols dictate that when cell phone respondents indicate they do not reside in the sampled state, a core portion of the interview is conducted and data are transferred to the state of current residence; therefore, the number of persons who have moved into and out of each state while retaining their cell phone 
numbers can be tracked. The purpose of this study was to compare respondents whose sampling state differs from the state of residence by moving in or out of the sampled state (movers) with other respondents (did not move) using the 2014 BRFSS cell phone data.

\section{METHODS}

The BRFSS completes interviews of all cell phone respondents who are adults, using overlapping sample frames. Persons contacted by cell phone are eligible even if they also have landline phones. We compared movers with respondents who did not move from cell phone survey by demographic factors, health care access, health status, health behaviors and chronic disease and conditions.

Two questions in the screening section of the BRFSS determined whether the respondent was in the correct sample. Respondents were asked whether they live in the sample state, and if they responded no, they were then asked about their state of residence. Data from out-of-state interviews were then transferred to the appropriate states at the end of each data-collection period and weighted to the state population. Due to lack of data on movers in the samples of Vermont (VT), Minnesota (MN), and the District of Columbia (DC), they were excluded from some of the analyses.

Demographic factors included gender (male and female); six age groups (18-24, 25-34, 35-44, 45-54, 55-64, and 65 or older); race/ethnicity (white non-Hispanic, black non-Hispanic, Hispanic, and other non-Hispanic); four categories of educational attainment ( $<$ high school, high school/GED, some post high school, and college graduate); and marital status (married or member of an unmarried couple, previously married, never married). General health status was dichotomized into good (included excellent, very good, or good health) and fair or poor health. Health-care coverage was defined as respondents having reported that they had private health insurance or prepaid plans among adults 18-64 years. Respondents who had one or more personal doctor or health care provider(s) were categorized to have specific source(s) of ongoing care.

No leisure time physical activity was defined from the respondents' indication of no participation in any physical activities or exercise (e.g., running, calisthenics, golf, gardening, or walking for exercise) other than their regular job during the preceding month. Respondents were classified as current smokers if they reported having smoked at least 100 cigarettes during their lifetime and indicated that they smoked every day or some days at the time of survey participation. Binge drinking was defined for men aged $\geq 18$ years as having on average 5 or more drinks during one occasion and for women aged $\geq 18$ years as having on average 4 or more drinks on one occasion during the preceding month. Self-reported weight and height were used to calculate body mass index (BMI) into categories of overweight and obese. We also looked at some self-reported chronic disease conditions including ever having arthritis, 
ever being diagnosed with diabetes or asthma, and/or depressive disorders. (For a full set of BRFSS questions and calculated variables, see Centers for Disease Control and Prevention 2015).

Respondents who did not answer, or refused, or answered "Do not know/not sure" to any study variables were excluded from analyses. SUDAAN (release 11.0, Research Triangle Institute, Research Triangle Park, NC) was used to account for the complex sample design of BRFSS. Chi-square tests $(P \leq 0.05)$ were used to compare groups of respondents. The unadjusted and adjusted (for demographics-sex, age, race/ethnicity, education, and marital status) prevalence ratio (PR) were obtained using LOGLINK (log-binomial) procedures to test the association of movers with health behaviors and chronic conditions.

\section{RESULTS}

Data from 162,880 cell phone interviews were available from 2014 BRFSS for analyses. There were $10.1 \%$ out-of-state interviews $(N=10,103) ; 54 \%$ of them were male, $43 \%$ aged 18 to 34 years, $12 \%$ were black non-Hispanic, $20 \%$ were Hispanics, $25 \%$ were college graduates, and nearly 50\% were married or member of an unmarried couple (Table 1). The estimated weighted population percentage of movers widely varied among participating states and ranged from $1.5 \%$ in Hawaii to $21.0 \%$ in Nevada, with a median of $5.8 \%$ (not shown in Table $1)$. 
Table 1 Demographic factors, health status, and health care access among movers and respondents who did not move, Behavioral Risk Factor Surveillance System (BRFSS) cell telephone survey 2014.

\begin{tabular}{|c|c|c|c|c|c|c|c|c|c|}
\hline \multirow[b]{3}{*}{ Total } & \multicolumn{3}{|c|}{ All cell phone adults } & \multicolumn{3}{|c|}{$\begin{array}{l}\text { Did not move } \\
(\mathrm{N}=152,777)\end{array}$} & \multicolumn{3}{|c|}{$\begin{array}{l}\text { Movers } \\
(\mathrm{N}=10,103)\end{array}$} \\
\hline & $\mathrm{N}$ & $\%$ & $95 \% \mathrm{Cl}$ & $\mathrm{N}$ & $\%$ & $95 \% \mathrm{Cl}$ & $\mathrm{N}$ & $\%$ & $95 \% \mathrm{Cl}$ \\
\hline & - & - & - & 152,777 & 89.9 & (89.6-90.1) & 10,103 & 10.1 & $(9.9-10.4)$ \\
\hline \multicolumn{10}{|l|}{ Gender } \\
\hline Male & 80,572 & 53.8 & $(53.4-54.2)$ & 75,346 & 53.7 & $(53.2-54.1)$ & 5,226 & 55.1 & $(53.6-56.5)$ \\
\hline Female & 82,308 & 46.2 & $(45.8-46.7)$ & 77,431 & 46.4 & $(45.9-46.8)$ & 4,877 & 44.9 & $(43.5-46.4)$ \\
\hline \multicolumn{10}{|l|}{ Age group * } \\
\hline $18-24$ years & 18,237 & 18.6 & $(18.2-19.0)$ & 16,658 & 18.2 & $(17.8-18.6)$ & 1,579 & 22.1 & $(20.8-23.4)$ \\
\hline $25-34$ years & 29,367 & 24.9 & $(24.5-25.3)$ & 26,251 & 23.7 & $(23.3-24.1)$ & 3,116 & 35.2 & $(33.8-36.6)$ \\
\hline $35-44$ years & 25,902 & 18.2 & $(17.9-18.6)$ & 24,319 & 18.4 & $(18.0-18.8)$ & 1,583 & 16.7 & $(15.6-17.8)$ \\
\hline $45-54$ years & 29,958 & 16.1 & $(15.8-16.5)$ & 28,823 & 16.9 & $(16.6-17.3)$ & 1,135 & 9.2 & $(8.4-10.0)$ \\
\hline $55-64$ years & 30,833 & 12.4 & $(12.1-12.7)$ & 29,590 & 12.8 & $(12.6-13.1)$ & 1,243 & 8.7 & $(8.0-9.5)$ \\
\hline 65 or more years & 26,917 & 9.8 & $(9.5-10.0)$ & 25,577 & 9.9 & $(9.7-10.2)$ & 1,340 & 8.2 & $(7.5-8.9)$ \\
\hline \multicolumn{10}{|l|}{ Race/Ethnicity* } \\
\hline White non-Hispanic & 119,067 & 58.1 & $(57.7-58.6)$ & 11,561 & 57.3 & $(56.9-57.8)$ & 7,506 & 65.1 & $(63.5-66.6)$ \\
\hline Black non-Hispanic & 12,163 & 12.5 & $(12.1-12.8)$ & 11,553 & 12.8 & $(12.5-13.1)$ & 610 & 9.3 & $(8.4-10.2)$ \\
\hline Hispanic & 16,365 & 20.1 & $(19.7-20.5)$ & 15,674 & 21.1 & $(20.7-21.5)$ & 691 & 11 & $(10.0-12.2)$ \\
\hline Other non-Hispanic & 12,689 & 9.4 & $(9.1-9.7)$ & 11,581 & 8.8 & $(8.5-9.1)$ & 1,108 & 14.6 & $(13.4-15.9)$ \\
\hline \multicolumn{10}{|l|}{ Education* } \\
\hline$<$ High school & 13,061 & 16 & $(15.6-16.4)$ & 12,682 & 17 & $(16.6-17.5)$ & 379 & 7.3 & $(6.4-8.4)$ \\
\hline High school/GED & 43,863 & 27.8 & $(27.4-28.2)$ & 41,974 & 28.5 & $(28.1-28.9)$ & 1,889 & 20.9 & $(19.8-22.1)$ \\
\hline Some post high school & 46,261 & 31.6 & $(31.2-32.1)$ & 43,662 & 31.6 & $(31.1-32.0)$ & 2,599 & 32.1 & $(30.6-33.5)$ \\
\hline College graduate & 58,198 & 24.6 & $(24.3-24.9)$ & 53,054 & 22.9 & $(22.5-23.2)$ & 5,144 & 39.7 & $(38.4-41.1)$ \\
\hline \multicolumn{10}{|l|}{ Marital status* } \\
\hline Married $†$ & 93,019 & 49.9 & $(49.4-50.3)$ & 87,515 & 50.1 & $(49.6-50.5)$ & 5,498 & 48.4 & $(47.0-49.9)$ \\
\hline Previously married & 33,407 & 18.3 & $(18.0-18.7)$ & 31,746 & 18.7 & $(18.4-19.0)$ & 1,661 & 15 & $(14.0-16.1)$ \\
\hline Never married & 34,940 & 31.8 & $(31.3-32.2)$ & 32,106 & 31.2 & $(30.8-31.7)$ & 2,834 & 36.6 & (35.1-38.0) \\
\hline
\end{tabular}




\begin{tabular}{|c|c|c|c|c|c|c|c|c|c|}
\hline & All cell phone adults & & & Did not move & & & Movers & & \\
\hline Reported fair or poor health * & 25,210 & 16.4 & $(16.1-16.8)$ & 24,236 & 17.3 & $(16.9-17.6)$ & 974 & 9.1 & $(8.3-10.0)$ \\
\hline Had health care coverage $18-64$ yrs. $^{*}$ & 113,302 & 79.4 & $(79.0-79.8)$ & 105,749 & 78.8 & (78.4-79.3) & 7,553 & 84.6 & $(83.4-85.8)$ \\
\hline Had specific source of care * & 124,152 & 69.4 & $(69.0-69.8)$ & 117,605 & 70.5 & (70.1-71.0) & 6,547 & 59.5 & $(58.0-61.0)$ \\
\hline
\end{tabular}

$\mathrm{CI}=$ Confidence interval.

${ }^{*}$ Factors significantly different between movers and respondents who did not move (chi-square test $\mathrm{P}$-value $<0.05$ ).

$\dagger$ Married or member of an unmarried couple. 
Compared with the respondents who did not move, movers were significantly more likely to be younger, disproportionately white non-Hispanics, college graduates, never married, and were more likely to have health care coverage. Movers were less likely to report poor health and a specific source for care than their counterparts did (Table 1$)$. A significant difference $(<0.05)$ persisted between movers and who did not move for demographic factors including age, race/ethnicity, education, marital status, health status, health care coverage (for 18 to 64 years), and specific source of care.

We extended our analyses to include health behaviors, history of chronic disease and chronic conditions (Table 2). Movers were significantly less likely to report no leisure time physical activity, to be current cigarettes smoker, overweight or obese, had been diagnosed with diabetes or arthritis or depression than those who did not move. However, movers were significantly more likely to binge drink than their counterpart. 
Table 2 Association of health behaviors and chronic conditions with movers and respondents who did not move, BRFSS cell telephone survey 2014 .

\begin{tabular}{|c|c|c|}
\hline Health behaviors and chronic conditions & Did not move & Movers \\
\hline \multicolumn{3}{|l|}{ No leisure time physical activity } \\
\hline Prevalence (\%) * & $23.3(22.9-23.7)$ & $15.2(14.1-16.4)$ \\
\hline UPR $(95 \% \mathrm{Cl}) \dagger$ & Referent & $0.65(0.61-0.70)$ \\
\hline $\operatorname{APR}(95 \% \mathrm{Cl}) \ddagger$ & Referent & $0.84(0.78-0.91)$ \\
\hline \multicolumn{3}{|l|}{ Current cigarette smoker } \\
\hline Prevalence (\%) * & $20.3(19.9-20.7)$ & $14.8(13.8-15.9)$ \\
\hline UPR $(95 \% \mathrm{Cl}) \dagger$ & Referent & $0.73(0.68-0.79)$ \\
\hline $\operatorname{APR}(95 \% \mathrm{Cl}) \ddagger$ & Referent & $0.83(0.77-0.89)$ \\
\hline \multicolumn{3}{|l|}{ Engaged in binge drinking } \\
\hline Prevalence (\%)* & $19.8(19.4-20.2)$ & $23.8(22.6-25.1)$ \\
\hline UPR $(95 \% \mathrm{Cl}) \dagger$ & Referent & $1.20(1.14-1.28)$ \\
\hline $\operatorname{APR}(95 \% \mathrm{Cl}) \ddagger$ & Referent & $1.05(0.99-1.11)$ \\
\hline \multicolumn{3}{|l|}{ Diagnosed with arthritis } \\
\hline Prevalence (\%) * & $19.4(19.0-19.7)$ & $13.4(12.5-14.4)$ \\
\hline $\operatorname{UPR}(95 \% \mathrm{Cl}) \dagger$ & Referent & $0.69(0.64-0.75)$ \\
\hline $\operatorname{APR}(95 \% \mathrm{Cl}) \ddagger$ & Referent & $0.88(0.83-0.95)$ \\
\hline \multicolumn{3}{|l|}{ Overweight or obese } \\
\hline Prevalence (\%) * & $63.4(62.9-63.9)$ & $54.2(52.7-55.7)$ \\
\hline UPR $(95 \% \mathrm{Cl}) \dagger$ & Referent & $0.85(0.83-0.88)$ \\
\hline $\operatorname{APR}(95 \% \mathrm{Cl}) \ddagger$ & Referent & $0.93(0.91-0.96)$ \\
\hline \multicolumn{3}{|l|}{ Had diabetes } \\
\hline Prevalence (\%) * & $8.2(8.0-8.5)$ & $4.4(3.9-4.9)$ \\
\hline UPR $(95 \% \mathrm{Cl}) \dagger$ & Referent & $0.53(0.47-0.60)$ \\
\hline $\operatorname{APR}(95 \% \mathrm{Cl}) \ddagger$ & Referent & $0.77(0.68-0.87)$ \\
\hline \multicolumn{3}{|l|}{ Ever had asthma } \\
\hline Prevalence (\%) & $13.8(13.5-14.1)$ & $13.4(12.4-14.5)$ \\
\hline UPR $(95 \% \mathrm{Cl}) \dagger$ & Referent & $0.97(0.90-1.05)$ \\
\hline $\operatorname{APR}(95 \% \mathrm{Cl}) \ddagger$ & Referent & $0.98(0.90-1.06)$ \\
\hline \multicolumn{3}{|l|}{ Ever had a depressive disorder } \\
\hline Prevalence (\%) * & $17.8(17.5-18.2)$ & $15.6(14.7-16.8)$ \\
\hline $\operatorname{UPR}(95 \% \mathrm{Cl}) \dagger$ & Referent & $0.88(0.82-0.94)$ \\
\hline $\operatorname{APR}(95 \% \mathrm{Cl}) \ddagger$ & Referent & $0.96(0.89-1.02)$ \\
\hline \multicolumn{3}{|l|}{ * P-value for the chi-square test is significantly different. } \\
\hline \multicolumn{3}{|l|}{$\dagger$ UPR, unadjusted prevalence ratio. } \\
\hline APR, adjusted prevalence ratio for sex, & & \\
\hline
\end{tabular}

We have also calculated the unadjusted prevalence ratio and adjusted prevalence ratio (APR) for movers. After adjusting for demographics, movers were $16 \%$ less likely $(\mathrm{APR}=0.8495 \%$ confidence interval $[0.78-0.91])$ to report no leisure time physical activity, $17 \%$ less likely $(\mathrm{APR}=0.83$ $[0.77-0.89])$ to be current cigarettes smoker, 7\% less likely $(\mathrm{APR}=0.93$ $[0.91-0.96])$ to be overweight or obese, 33\% less likely $(\mathrm{APR}=0.77$ $[0.68-0.87])$ to report diabetes, and $12 \%$ less likely $(\mathrm{APR}=0.88[0.83-0.95])$ to report arthritis compared to respondents who did not move. 


\section{DISCUSSION}

In the United States, $10 \%$ of adults who use cell phones live in a state that is different from their sampling state. This state-level estimate of movers is lower than the previous studies conducted by (Skalland and Khare 2013) but very similar to state-level inaccuracy of cell phone samples reported by (Benf ord et al. 2012) and (Christian, Dimock, and Keeter 2009). Previous studies on the inaccuracy of cell phone samples included cell phone-only households where interviews are attempted only for adults in cell phone-households not accessible through the landline sampling frame. However, the BRFSS uses an overlapping or take-all design (A.A.P.O.R.Cell Phone Task Force 2010) where interviews are attempted for adults in cell phone-households regardless of their landline usage. Like the findings of previous studies, our study suggests similar demographic characteristics of this mobile population. The out-of-state respondents were significantly more likely to be younger, disproportionately white non-Hispanics, college graduates, as well as never married; movers also were more likely to have health care coverage than individuals who did not move.

Our study is the first population-based study to explore the association between this mobile population and their health behaviors (e.g., smoking, physical activity); chronic disease (diabetes, arthritis); and chronic conditions (overweight and obesity). Results indicate that this mobile population are more physically active, not a current smoker, not overweight or obese, and have lower prevalence of depression, diabetes, and arthritis compared to those who did not move. Thus, not including the out-of-state respondents in any population-based cell phone survey may bias the estimates of leisure time physical activity, smoking status, binge drinking, and chronic conditions like diabetes, arthritis, and depression. According to (Skalland and Khare 2013), in a single-state telephone survey, excluding the out-of-state respondents will increase the cost of the survey, as more cell phone samples are needed to complete the target number of interviews. They suggested adding a measure of mobility in the weight adjustment to reduce potential noncoverage bias. Since BRFSS data is collected from all the states, and the out-of-state respondents are transferred to the state of residence, this protocol helps avoid the potential for bias more effectively than surveys limited to individual state or sets of states. However, other surveys that do not include this transfer of data are likely to suffer bias on estimates of health-related outcomes.

\section{LIMITATIONS}

Our study does have some limitations. Two states (VT and MN) and the DC did not complete the screening question to identify out-of-state persons within their samples. Differing sample sizes and sampling designs among the states may have also had an effect on the percentages, especially among persons moving into states. 


\section{CONCLUSION}

As the U.S. population continues to rely on cell phones (Blumberg and Luke 2 016), telephone surveys will continue to increase the proportion of cell phone interviews, or rely on cell phones exclusively. BRFSS will continue to monitor the demographics, health behaviors, and chronic disease and conditions among persons who kept their cell phone numbers after moving from one geographic location to another, as well as continue to track the locations of movers both in and out of states.

\section{DISCLAIMER}

The findings and conclusions in this article are those of the authors and do not necessarily represent the official position of the Centers for Disease Control and Prevention. 


\section{REFERENCES}

A.A.P.O.R.Cell Phone Task Force. 2010. "New Considerations for Survey Researchers When Planning and Conducting RDD Telephone Surveys in the U.S. with Respondents Reached via Cell Phone Numbers.” Deerfield, IL. http://www.aapor.org/AAPOR_Main/media/MainSiteFiles/ 2010AAPORCellPhoneTFReport.pdf.

Benford, R., L. Piekarksi, J. Lien, and T. Thompson. 2012. "Geographic Differences between RDD Cell and Landline Frames and Self-Report." In American Association for Public Opinion Research Conference. Orlando, FL.

Blumberg, S.J., and J.V. Luke. 2016. "Wireless Substitution: Early Release of Estimates from the National Health Interview Survey, July-December 2015.” National Center for Health Statistics. https://www.cdc.gov/nchs/data/nhis/earlyrelease/Wireless201605.pdf.

Christian, L., M. Dimock, and S. Keeter. 2009. "Accurately Locating Where Wireless Respondents Live Requires More than a Phone Number.” Washington DC, Pew Research Center. http:/pewresearch.org/pubs/1278/cell-phones-geographic-samplingproblems.

Guterbock, T., P.J. Lavrakas, T.N. Tompson, and R.Z. Wallack. 2011. “Cost and Productivity Ratios in Dual-Frame Rdd Telephone Surveys.” Survey Practice 4 (2).

Kempf, A.M., and R.L. Remington. 2007. "New Challenges for Telephone Survey Research in the Twenty-First Century." Annual Review of Public Health 28 (1): 113-26.

Lavrakas, P.J., C.D. Shuttles, C. Steeh, and H. Fienberg. 2007. "The State of Surveying Cell Phone Numbers in the United States." Public Opinion Quarterly 71 (5): 840-54.

Marken, S., M. Chattopadhyay, and A. Chan. 2016. "Covering Our Most Mobile Users: Identifying Which States Are Most Susceptible to Coverage Error and How Sampling Rate Centers in Adjoining States Can Help." In American Association for Public Opinion Research Conference. Austin, TX.

Skalland, B., and M. Khare. 2013. "Geographical Inaccuracy of Cell Phone Samples and the Effect on Telephone Survey Bias, Variance, and Cost." Journal of Survey Statistics and Methodology 1 (1): $45-65$. 
FIGURES, TABLES, AND SUPPLEMENTARY MATERIALS

Table 1 Demographic factors, health status, and health care access among movers and respondents who did not move, Behavioral Risk Factor Surveillance System (BRFSS) cell telephone survey 2014.

Download: http://app.scholasticahq.com/api/v1/attachments/9470/download 